\title{
An experimental study of the selective oxidation of ethene in a wall cooled tubular packed bed reactor
}

\author{
P.C.Borman and K.R.Westerterp ${ }^{\ddagger}$ \\ Chemical Reaction Engineering Laboratories, University of Twente, \\ P.O.Box 217, 7500 AE Enschede, the Netherlands
}

₹ Author to whom correspondence should be addressed

\begin{abstract}
The selective oxidation of ethene over a silver on $\alpha$-alumina catalyst was studied in a wall cooled tubular reactor. Temperatures were measured inside the bed at different axial and radial positions as well as the overall conversion and selectivity. Locally measured temperatures vary after repacking the bed whereas the global properties do not vary. Angular variations in temperature cannot be described by present day models. The steady state temperature profiles in the packed bed and overall conversion and selectivity as function of different operating conditions are discussed.
\end{abstract}

\section{Introduction}

Highly exothermic heterogeneously catalysed chemical reactions are often carried out in tubular packed bed reactors because of their large heat transfer area per unit of reactor volume. Control of the temperature level in the packed bed is vital to maintain selectivity, to prevent catalyst deactivation or run away. When developing a cooled tubular reactor for a new process, the development engineer will therefore have to evaluate the behaviour of tubes of different diameters at different operating conditions to establish a proper design. Much time and money can be saved when proper design models and procedures are available. To test the reliability of models for this type of reactor, we investigate in our laboratories the highly exothermic ethene oxidation to ethene oxide, carbon dioxide and water over an industrial, ring shaped silver on $\alpha$-alumina catalyst. In this interim paper we will present some results of our continuing research. The relevant reactions are:

$$
\begin{array}{ll}
\mathrm{C}_{2} \mathrm{H}_{4}+\frac{1}{2} \mathrm{O}_{2} \rightarrow \mathrm{C}_{2} \mathrm{H}_{4} \mathrm{O} & \Delta \mathrm{H}=-105 \mathrm{~kJ} / \mathrm{mole} \text { ethene } \\
\mathrm{C}_{2} \mathrm{H}_{4}+2 \frac{1}{2} \mathrm{O}_{2}-2 \mathrm{CO}_{2}+2 \mathrm{H}_{2} \mathrm{O} & \Delta \mathrm{H}=-1323 \mathrm{~kJ} / \mathrm{mole} \text { ethene }
\end{array}
$$

The oxidation of ethene in our study is, contrary to industrial practice, carried out with air in excess and operated under the lower explosion limit of 3 vol\% ethene in air. No chlorine-modifier is added to the feed gas.

\section{Kinetics}

The kinetics of the reactions are studied separately in an internal recycle reactor. The following equations were obtained for the production rates of ethene oxide (1) and carbon dioxide (2): 


$$
R_{t}=\frac{k_{r}^{i} P_{E}}{1+K_{E}^{i} P_{E}+K_{C}^{i} P_{C}+K_{H}^{i} P_{H}+K_{B O}^{i} P_{E O}} P_{o}^{n_{t}}
$$

$\begin{array}{llll}k_{r}{ }^{\prime}=0.2572 \exp (-8068 / \mathrm{T}) & k_{r}{ }^{2}=178 \exp (-11381 / \mathrm{T}) & K_{E}{ }^{\prime}=.30 \cdot 10^{-3} & K_{E}{ }^{2}=.49 \cdot 10^{-3} \\ K_{C}{ }^{\prime}=.87 \cdot 10^{-3} & K_{C}{ }^{2}=1.14 \cdot 10^{-3} & K_{E O}=.90 \cdot 10^{-3} & K_{E O}{ }^{2}=.49 \cdot 10^{-3} \\ K_{H}{ }^{\prime}=3.68 \cdot 10^{-6} \exp (2370 / \mathrm{T}) & K_{H}{ }^{2}=4.04 \cdot 10^{-7} \exp (3430 / \mathrm{T}) & n_{I}=0.13 & n_{2}=0.14\end{array}$

These semi-empirical relations fit the kinetic experiments, in which the partial pressures of $\mathrm{O}_{2}, \mathrm{C}_{2} \mathrm{H}_{4}$, $\mathrm{CO}_{2}$ and $\mathrm{EO}$ were systematically varied, with an average error of $19 \%$. They were obtained for $600<\mathrm{P}_{\mathrm{E}}<18 \cdot 10^{3} \mathrm{~Pa}, \quad 100<\mathrm{P}_{\mathrm{W}}<14 \cdot 10^{3} \quad \mathrm{~Pa}, \quad 200<\mathrm{P}_{\mathrm{EO}}<12 \cdot 10^{3} \quad \mathrm{~Pa}, \quad 200<\mathrm{P}_{\mathrm{C}}<15 \cdot 10^{3} \quad \mathrm{~Pa}$, $110<\mathrm{P}^{\circ}<2.010^{5} \mathrm{~Pa}$ and temperatures between 181 and $253^{\circ} \mathrm{C}$. Only a small influence of the partial pressure of $\mathrm{O}_{2}$ on the reaction rates was found. $\mathrm{CO}_{2}$ strongly inhibits both reactions; the inhibiting effect on the combustion reaction is stronger than that on the epoxidation reaction. Also ethene oxide and water inhibit the reactions. Ethene oxide inhibits the epoxidation stronger than the combustion reaction. Water inhibits both reactions equally strong. Full details on the kinetic investigations will be published in the near future.

\section{The experimental apparatus}

Experiments were performed in a bed with a length of $0.45 \mathrm{~m}$ and a diameter of $53 \mathrm{~mm}$, see Borman et al. (1992), packed with ring shaped catalyst particles of $d_{\text {eff }}=6.2 \mathrm{~mm}$. The wall of the reactor is cooled externally with pressurized boiling water. In the tube a frame is inserted to measure temperatures at different radial and axial positions, see figure 1 . The frame is a type of ladder built of two stainless steel rods with an outer diameter of 1.5 and an inner diameter of $0.8 \mathrm{~mm}$, with rungs made of a temperature resistant polymer with a low thermal conductivity of $0.4 \mathrm{~W} / \mathrm{mK}$. In the rungs holes are drilled with a diameter of $0.55 \mathrm{~mm}$ in which thermocouples type $\mathrm{K}$, with a diameter of $0.5 \mathrm{~mm}$, are fixed at different radial positions. The thermocouples are bound in bundles to the rods and leave the reactor through a pressure seal; 32 temperatures are measured simultaneously in the catalyst bed. Temperatures at different radial positions and at different axial locations were measured in the packing, along with the catalyst particle temperatures on the centre line of the tube. The reactor feed and effluent gas were analyzed using a gas chromatograph. Experiments were performed with different feed compositions at pressures varying between 0.3 and 0.8 $\mathrm{MPa}$ at wall temperatures between 164 and $214^{\circ} \mathrm{C}$, at Reynolds numbers varying between 150 and 300 , the superficial gas velocities varied between 0.1 and $0.4 \mathrm{~m} / \mathrm{s}$. In all experiments it was ensured that the temperature of the gas entering the packed bed was equal to the wall temperature. 
Results

From preliminary experiments it became clear that catalyst activity varied between different samples of the same catalyst batch. To ensure compatibility of the kinetic study and the packed bed reactor study it was chosen to activate a large amount of catalyst by exposing it to reaction for approximately 100 hours until changes in activity were no longer found. Samples of this catalyst were used in both studies.

Some typical temperature profiles are shown in figure 2. Because temperatures were neither averaged between bed packings nor along a radial circumference, scatter is observed. The scatter is specific for a certain packing and is probably determined by the incidental position of the thermocouples with respect to the catalyst particles. Repeating an experiment after repacking the bed results only in changes of local temperatures, see figure 2 , no overall variations in conversion and selectivity are observed, see figure $5 \mathrm{c}$.

A packed bed is inhomogeneous: at a certain axial position temperatures will not be constant along a radial circumference. A fictitious example of this angular variation is given in figure 3 . This effect has been noticed without reaction by other investigators performing steady state heat transfer experiments, see e.g. Cresswell (1987), Dixon (1988) and Borkink (1991). In heat transfer studies the temperatures are averaged and the variation is treated as though it was due to random measurement error. The amplitude of such variations increases when moving from the centre to the wall of the reactor. The amplitude is significant when compared to the temperature difference between the tube centre and the wall. Under reaction conditions the implications of these effects might even be more severe because of the strong dependence of the reaction rate on temperature. It has to be realized that any deterministic model of the reactor only predicts temperatures averaged for a radial circumference. This hampers comparison of locally measured and calculated temperatures. In how far the models which neglect these effects, are still capable of describing the reactor behaviour remains to be seen.

In none of the experiments differences between gas and the catalyst particle temperatures in the centre-line exceeding $3 \mathrm{~K}$ were observed. In figure 4 results of experiments in which different operating conditions are varied are presented as "mean-cup" temperatures defined as

$$
T_{M C} \equiv \frac{2}{R_{t}^{2}} \int_{r=0}^{R_{t}} r T(r) d r \text {. In figure } 5 \text { the corresponding values of the overall conversion and selectivity }
$$

towards ethene oxide are presented.

Figures $4 \mathrm{a} / 5 \mathrm{a}$ show the influence of increasing the wall temperature. The conversion of ethene increases while selectivity towards ethene oxide decreases as was expected: the apparent activation energy for the epoxidation is smaller than that of the total oxidation reaction, as can be verified from the kinetic relations. Increasing the mass flow, while keeping the mole fraction of ethene in the feed and the other operating conditions constant, see figures $4 b$ and $5 b$, results in lower hot-spot temperatures and a decrease of the ethene conversion, the selectivity increases slightly. Increasing the mole fraction of ethene in the feed, keeping the other operating conditions constant, see figures $4 \mathrm{c} / 5 \mathrm{c}$, results in increased hot spot temperatures due to the increased adiabatic temperature rise. Adding carbon dioxide to the feed gas, see figures $4 d / 5 d$, decreases the hot spot temperature and the ethene conversion whereas the selectivity increases, showing the important role of $\mathrm{CO}_{2}$ partial pressure in the kinetics of the reactions. The selectivity increase is a result of both decreased temperatures in the bed and the effect of $\mathrm{CO}_{2}$ on the kinetics of the reactions. 

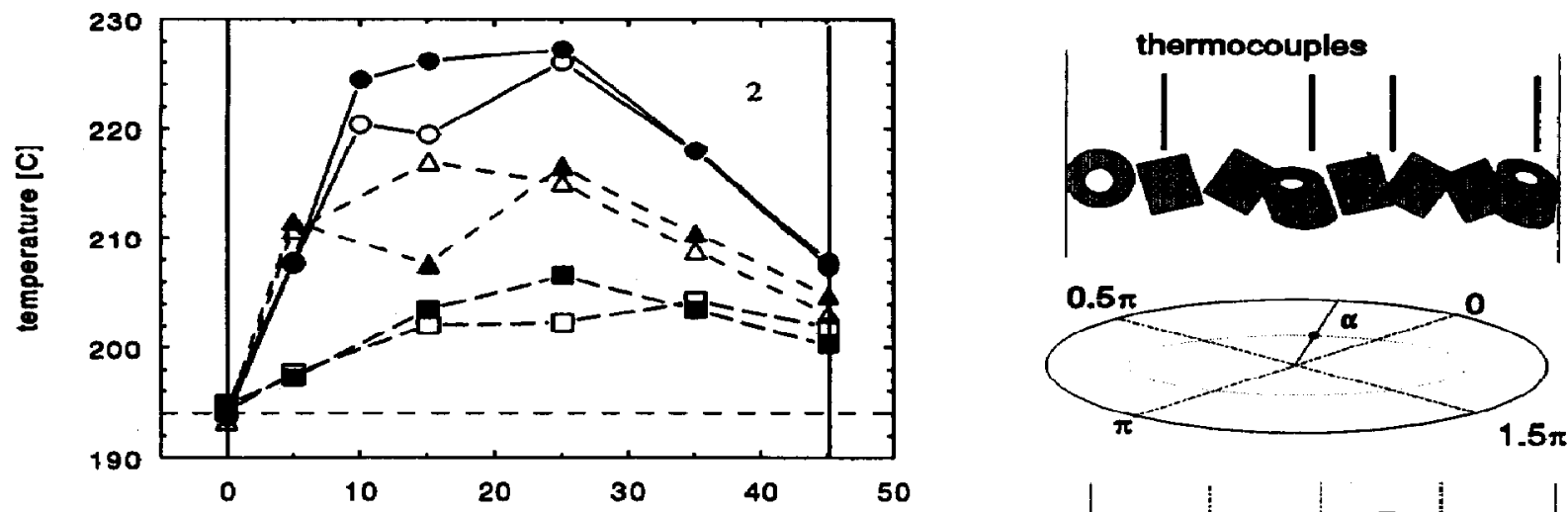

bed length [cm]

Figure 2 Influence of repacking on axial temperature profiles. gas tempaeratures $O: r=0 \mathrm{~mm}, \Delta: r=16 \mathrm{~mm}, \square: r=25 \mathrm{~mm}$; closed symbols : after repacking the bed. Experimental conditions: $\mathrm{x}_{\mathrm{B}}{ }^{0}=0.815 \%, \mathrm{P}=5$ bar, $\mathrm{T}_{\mathrm{w}}=194^{\circ} \mathrm{C}, \rho_{\mathrm{s}} \mathrm{v}=0.81 \mathrm{~kg} / \mathrm{m}^{2} \mathrm{~s}$.

Figure 3 Illustration of the variation of the gas temperature inside the packed bed at a certain axial position along a radial circumpherence.
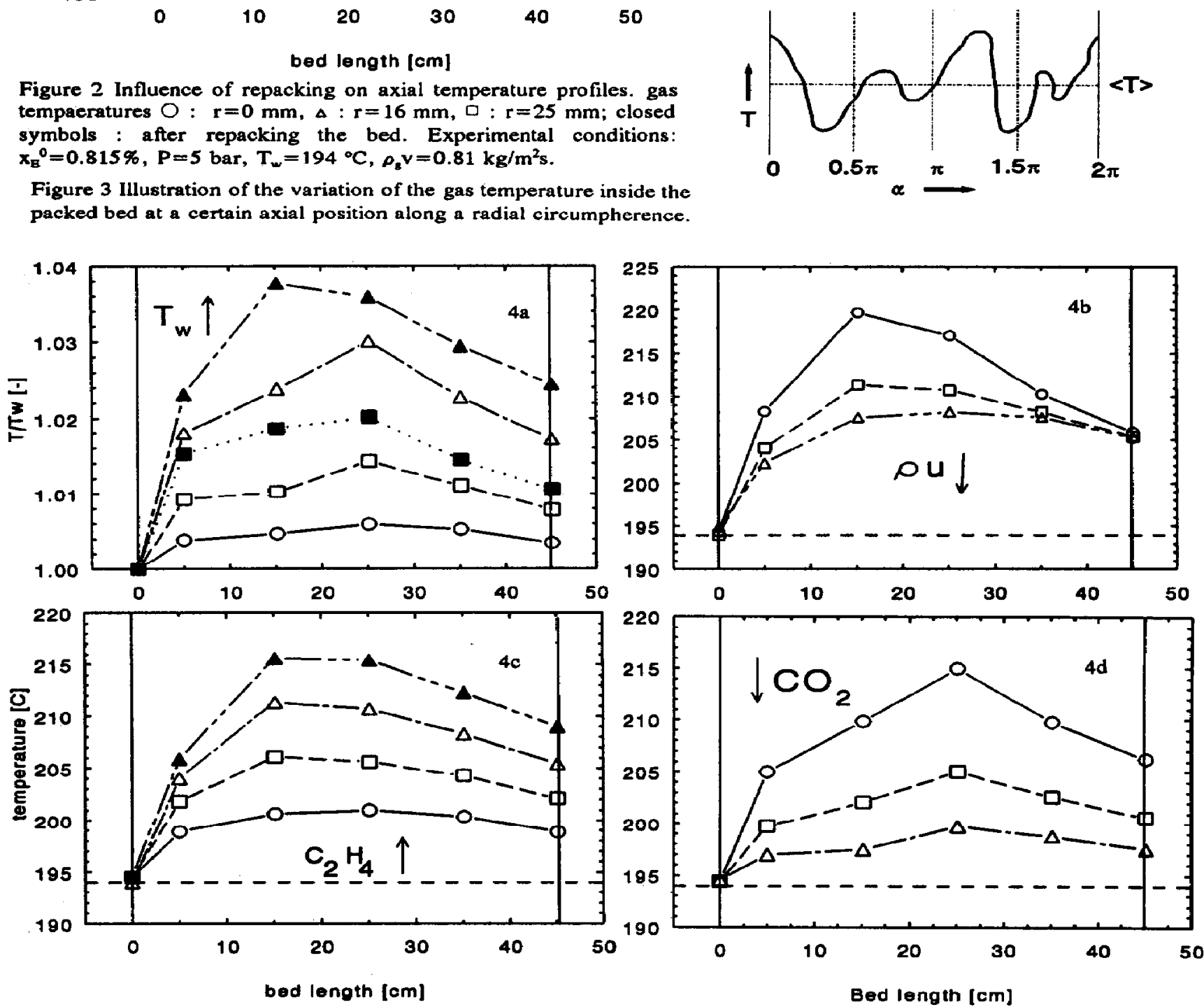

Figure 4 Experimental mean-cup temperature profiles:

(A) Influence of the wall temperature, $P=5$ bar, $\rho_{g} v=0.81 \mathrm{~kg}^{2} \mathrm{~m}^{2}, x_{E}^{0}=0.4 \%, T_{w}: 0164, \square 184, \square 194, a 204$, $\triangle 214^{\circ} \mathrm{C}$

(B) Influence of the mass flow rate, $P=5$ bar, $T_{w}=194^{\circ} \mathrm{C}, x_{E}{ }^{0}=0.82 \%, \rho_{z} v: 00.55,00.81, \Delta 1.09 \mathrm{~kg} / \mathrm{m}^{2} 8$;

(C) Influence of the mole fraction ethene in the reactor feed, $P=5$ bar, $T_{w}=194^{\circ} \mathrm{C}, \rho{ }_{k} v=0.81 \mathrm{~kg} / \mathrm{m}^{2} \mathrm{~s}, x_{E}{ }^{\circ}: \Delta 0.96$, $\Delta 0.82,00.56,00.26 \%$.

(D) Influence of the mole fraction carbon-dioxide in the reactor feed, $P=5$ bar, $T_{w}=194^{\circ} \mathrm{C}, X_{E}^{0}=0.81 \%, P_{z} v=0.81$ $\mathrm{kg} / \mathrm{m}^{2} \mathrm{~s}, \mathrm{x}_{\mathrm{CO} 2}{ }^{0}$ : $0.00, \square 0.22, \Delta 0.66 \%$. 

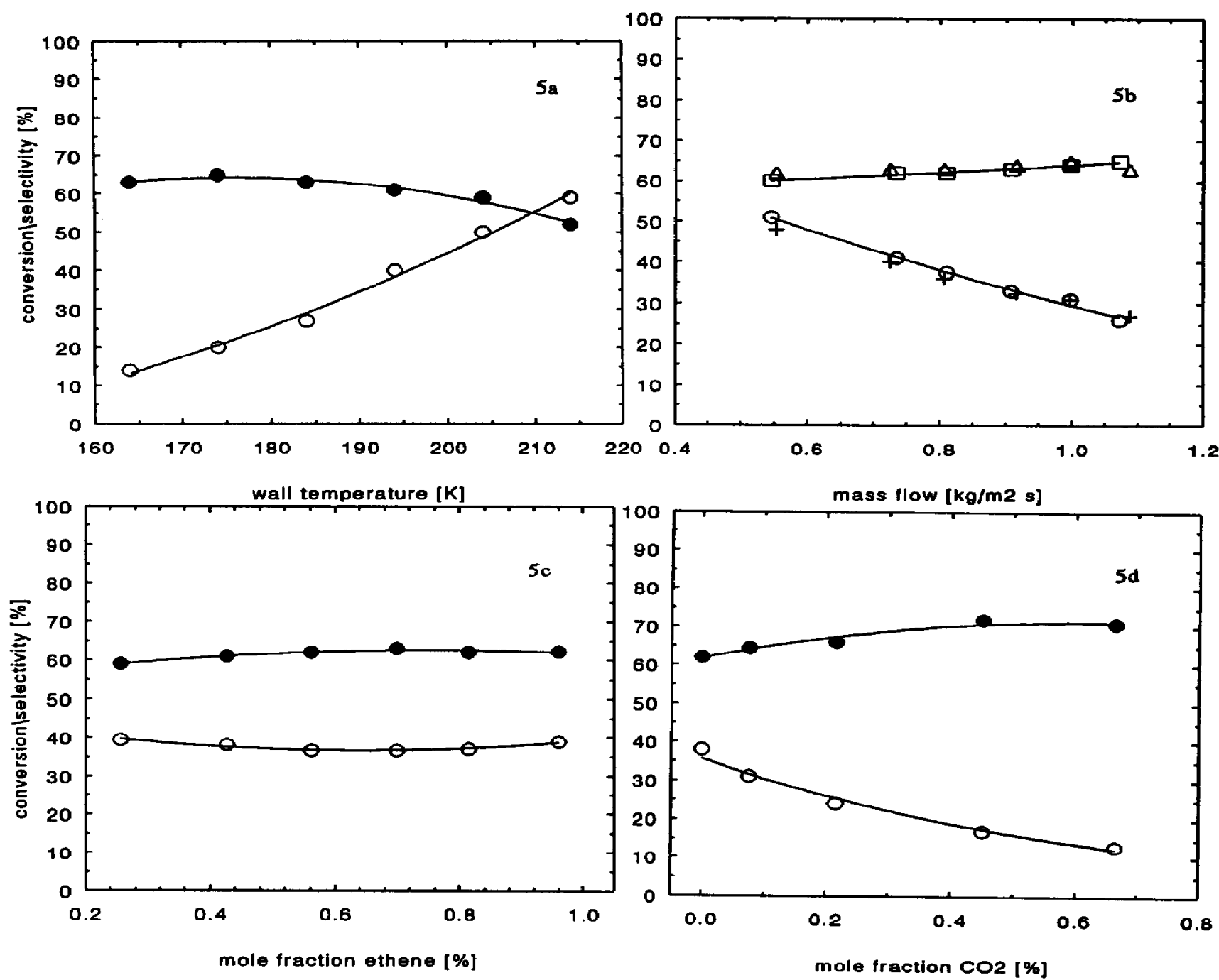

Figure 5 Experimental conversion of ethene $(O)$ and selectivity $(O)$ towards ethene oxide for the experiments shown in figure 4a, b, c and $d$. In figure $5 c$ also the influence of repacking the bed on conversion and selectivityis shown: $\square$, $A$ : selectivity; $O,+$ : conversion.

The experiments were compared to model calculations performed with a pseudo-homogeneous two dimensional model. Using the above mentioned kinetic relations and separately determined heat transfer parameters, see Borman et al. (1992), only a fair agreement could be obtained between the measured and experimental temperature profiles. Though no final reason can be given yet, we feel the poor model description is due to inaccuracies in the kinetic relations.

\section{Conclusions}

The temperature profiles for our packing with only about 8 particles on a tube diameter exhibit a large scatter, due to angular variations of the temperature in a packed bed. These variations cannot be described using deterministic models as they are due to the structure of the bed packing.

In the oxidation of ethene the inhibition of the reaction rates by reaction products is of major importance when modelling the reactor. The accuracy of our kinetic relations will have to be improved to enable further studying of packed bed reactor modelling, heat transfer characteristics of the packed bed with and without reaction and the impact of the angular temperature variations. 


\section{Notation}

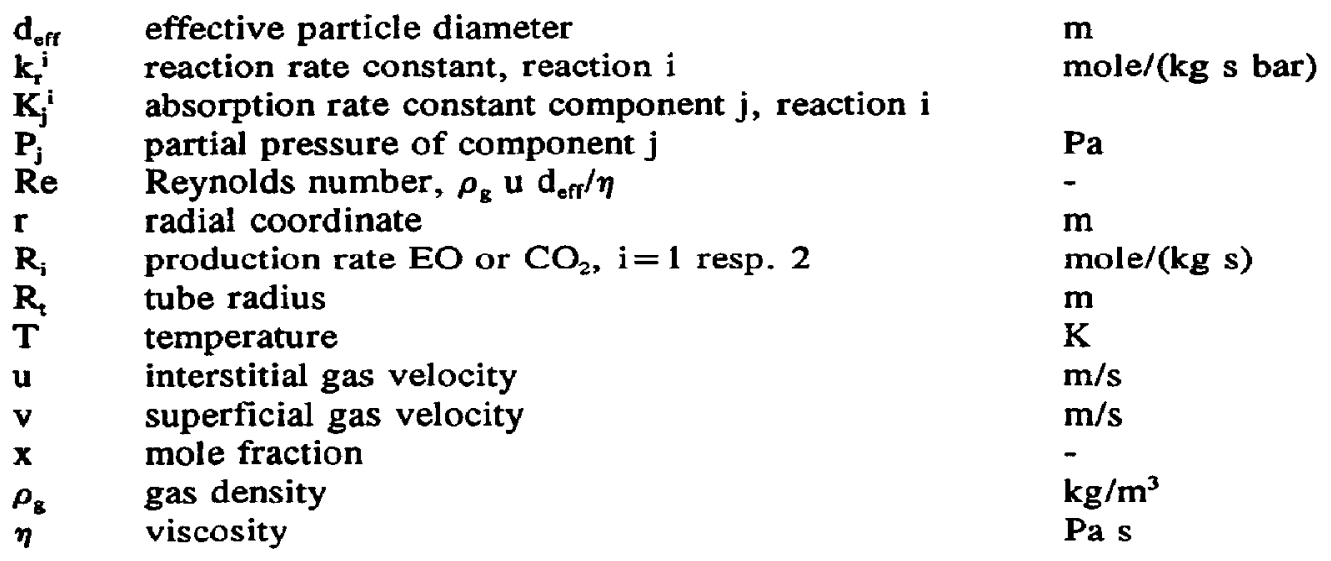

Super and subscripts
C : carbon dioxide
$E$ : ethene
EO : ethene oxide
W : water
MC : mean cup
w : wall
0 : inlet

\section{References}

Borkink J.G.H.; Heat transport in wall-cooled packed beds with a low tube-to-particle diameter ratio; Thesis Twente university, 1991

Borman P.C., Borkink J.G.H., Westerterp K.R.; 1992; Heat transport in a wall heated tubular packed bed reactor at elevated pressures and temperatures; accepted for publication by Chem. Eng. Commun.

Cresswell D.L.; 1987; Heat transfer in packed bed reactors; in Chemical Reactor Design \& Technology, ed. H.1. de Lasa; NATO ASI series, applied sciences nr 110.

Dixon A.A.; 1988; Wall and particle shape effects on heat transfer in packed beds; Chem. Eng. Commun., 71, pp. 217-237

These investigations were supported by the Netherlands Foundation for Chemical Research SON with financial aid from the Netherlands Technology Foundation. 